\title{
M-系列信号を用いた最適化制御*
}

\author{
大 地 成 治**.古 田 勝 久*** \\ 伊 沢 計 介***
}

\section{Optimizing Control Using M-sequences}

\author{
Shigeharu Онсні, Katsuhisa Furuta \\ and Keisuke Izawa
}

Sinusoidal perturbation signal has been usually used in optimizing control systems. But the sinusoidal perturbation causes some difficulties or disadvantages, (1) when the process has unknown or variable dynamic characteristics, or (2) when the simultaneous optimization of a multi-variable process is aimed.

Psuedo-random binary perturbation signals can get rid of these disadvantages due to the sinusoidal perturbation.

In this paper, M-sequence signal is used as the pseudo-random binary perturbation signal, and experimental and theoretical study on the optimization of processes with variable dynamic characteristics and on the simultaneous optimization of two-variable processes is described.

\section{1. まえがき}

最適化制御を必要とするプロセスにおいては, 注目 している入力-出力関係が一般の線形制御系のような (線形あるいは単調)関係にはなく極値をもつのが普通 である.もしこの極值をもつ関数,すなわち目的関数 (objective function) が時間的に変化しないものなら ば, 最初に入力を最適值に設定しさえすれば以後なん らの問題も生じない.しかし実際には, プロセスの運 転中では測定も制御もできず，かつ時間的に変化する ような変数の関数に目的関数がなっている場合がある. たとえば触媒の活性などはそのような変数の例である.

Fig. 1 は時間的に変動する目的関数の例である. このような特性をもつプロセスでは極值（最適点）が 運転中に動いてしまい，運転開始時には最適になるよ らに入力を設定してもその後は最適状態からずれてし まうかもしれない。したがって最適化制御に执いては, 極值の探索が最も重要な問題である.

さて, 直接に試行実験を行ない極值を探索する最適 化制御には頂点保持法 (peak holding method), 摂 動法 (perturbation method) ら ${ }^{12) 33}$ がある. 頂点保 持法は C.S. Draper 拈よび Y.T.Li が航空機用の内

* 昭和 41 年 4 月 4 日受付

** 富士写真フイルム株式会社
*** 東京工業大学

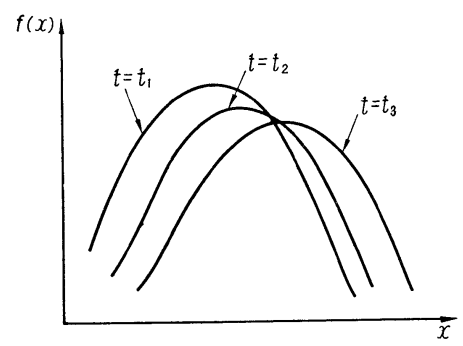

Fig. 1 An example of objective function with time variable parameter

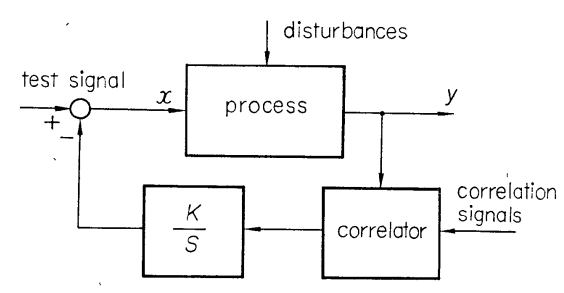

Fig. 2 Optimizing conrol system with correlator

燃機関の最適化制御に試みた方法である ${ }^{4)}$ 。たた，摂 動法は極值を探索するための探索信号（摂動信号）を 入力に加える方法である. 捸動法のうちで, 相関器を 用いて目的関数の傾きを求める方法が相関形摂動法で ある (Fig. 2). 摂動法において, 入力に加兄る探索 信号としては周期信号ならば任意の形のものが使用で 
きるが一般には正弦波信号が用いられる。しかし正弦 波信号を用いる摂動法ではつぎのような場合に問題が 生じる。

（1）プロセスの動特性が未知である場合，あるい はプロセスの動特性が時間的に変化するか，ま たは入力の値により変化する場合.

（2）多変数プロセスの同時最適化制御を行なら場 合.

動特性の変動の問題に対し， P.Eykhoff 特よび O.

J.M.Smith はプロセスのモデルを用いて相関信号の 位相を調節する方法を考案したが5)，この方法はプロ セスのモデルを作らねばならないといら点に問題があ る.

これに対し，探索信号としてランダム信号を用いる 方法ではプロセスの動特性を測定し, 重み関数の面積 からプロセスのゲイン，すなわち目的関数の傾きを決 定することができ，動特性の変動は正弦波を使用する 場合ほど問題にならない。また，ランダム信号を用い れば多変数プロセスの同時最適化制御も可能である. Grinten $\left.{ }^{6}\right)$ はランダム信号を探索信号として用いた多 变数同時最適化制御を試みている。また，擬似ランダ ム二進信号を探索信号として用いることもできる778). 本論文では，探索信号として擬似ランダム二進信号で ある $\mathrm{M}$ 一系列信号を応用した最適化制御系の解析を行 ない，アナログ電子計算機による検討を行なった。

\section{2. 一变数最適化制御}

最適化制御を行ならプロセスの伝達関数は，操業入 力 $\bar{x}$ 和よび外乱 $u$ の関数であり, $G(s, \bar{x}, u)$ と表わ すことができる.プロセスの入力を $x$ とすると，目的 関数 $f(x, u)$ と $G(0, \bar{x}, u)$ の間にはつぎの関係が成 立する.

$$
\left.\frac{\partial f(x, u)}{\partial x}\right|_{x=\bar{x}}=G(0, \bar{x}, u)
$$

$f(x, u)$ は Fig. 1 の例のように極值を一つもつ関数 でその極点を最適点と考光る. 着目する $\bar{x}$ の範囲を

$$
\bar{x}_{*} \leq \bar{x} \leq \bar{x}^{*}
$$

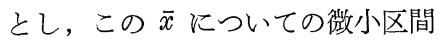

$$
\bar{x}-a \leq x \leq \bar{x}+a
$$

に执いては $f(x, u)$ が線形近似できるものとする。す なわち, (3) 式の $x$ について $f(x, u)$ は次式で近 似できるものとする.

$$
f(x, u) \doteqdot f(\bar{x}, u)+\beta_{1}(\bar{x}, u) \cdot(x-\bar{x})
$$

ただし，

$$
\beta_{1}(\bar{x}, u)=\left.\frac{\partial f(x, u)}{\partial x}\right|_{x=\bar{x}}
$$

いま，探索信号として Fig. 3(a) に示すような土 $a$ の值をもつ周期 $N \Delta$ の M-系列信号 $\hat{x}(t)$ を $\bar{x}$ に 加光る.

$$
x(t)=\bar{x}+\hat{x}(t)
$$

$\bar{x}$ 拈よび $u$ は $\hat{x}(t)$ に比べじゅうぶん変化の括そい ものとし，プロセスの重み関数を $g(\tau, \bar{x}, u)$ とすると， プロセスの入出力間には $(7)$ 式の関係が成立する.

$$
y(t)=\int_{0}^{\infty} g(\alpha, \bar{x}, u)\{\bar{x}+\hat{x}(t-\alpha)\} d \alpha \cdots
$$

つぎに，Fig.3(b) のような 1，0 の値をとる M-系 列信号を $x^{\circ}$ とし， $(7)$ 式の両辺と $x^{\circ}(t)$ との相関 をとると，

$$
\begin{aligned}
& \frac{1}{N \Delta} \int_{0}^{N \Delta} x^{\circ}(t-\tau) \cdot y(t) d t \\
& =\frac{1}{N \Delta} \int_{0}^{N \Delta} x^{\circ}(t-\tau) \int_{0}^{\infty} g(\alpha, \bar{x}, u)\{\bar{x}+\hat{x}(t-\alpha)\} d \alpha d t
\end{aligned}
$$

（8）式を変形すると次式が得られる.

$$
\int_{0}^{\infty} g(\alpha, \bar{x}, u) \cdot \phi_{x^{\circ} \hat{x}}(\tau-\alpha) d \alpha=\phi_{x^{\circ} y}(\tau)-\phi_{x^{\circ} \bar{y}}
$$

ただし，

$$
\begin{aligned}
\phi_{x^{\circ} \hat{x}}(\tau) & =\frac{1}{N \Delta} \int_{0}^{N \Delta} x^{\circ}(t-\tau) \hat{x}(t) d t \\
\phi_{x^{\circ} y}(\tau) & =\frac{1}{N \Delta} \int_{0}^{N \Delta} x^{\circ}(t-\tau) y(t) d t \\
\phi_{x^{\circ} \bar{y}} & =\frac{1}{N \Delta} \int_{0}^{N \Delta} x^{\circ}(t-\tau) \bar{y} d t
\end{aligned}
$$

ここで, $\bar{y}$ は出力 $y$ のらち $\bar{x}$ に対応する成分である. $\mathrm{M}$-系列信号 $x^{\circ}(t)$ と $\hat{x}(t)$ の相関関数 $\phi_{x^{\circ} \hat{x}}(\tau)$ は Fig. 3(c) に示すような関数であり，そのパワースペ クトル密度 $\Phi_{x \circ \hat{x}}(\omega)$ は $\omega$ の小さな範囲に叔いてつぎ の関係を満足する.

$$
\Phi x^{\circ} \hat{x}(\omega) \doteqdot \Phi_{x^{\circ} \hat{x}}(0)
$$
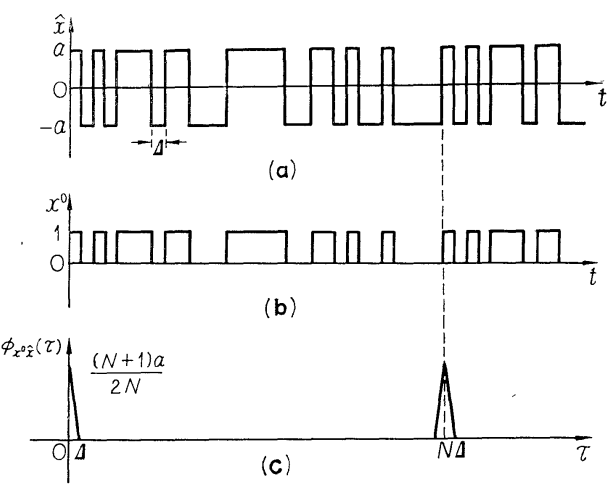

Fig. 3 (a), (b) $\mathrm{M}$-sequences $(N=31)$ (c) Correlation function $\phi_{x} \circ \hat{x}(\tau)$ 
また， $\Phi_{x^{\circ} \hat{x}}(0)$ と $\phi_{x^{\circ} \hat{x}}(\tau)$ の間にはつぎの関係があ る.

$$
\Phi_{x^{\circ} \hat{x}}(0)=\int_{0}^{N \Delta} \phi_{x^{\circ} \hat{x}}(\tau) d \tau
$$

したがって，

$$
\Phi_{x^{\circ} \hat{x}}(0)=\frac{(N+1)}{2 N} a \Delta
$$

(9)，(13)，(15) 式から $g(\tau, \bar{x}, a)$ はつぎのように 表わされる。

$$
g(\tau, \bar{x}, u) \doteqdot \frac{2 N}{(N+1) a \Delta}\left\{\phi_{x^{\circ} y}(\tau)-\phi_{\circ} x \bar{y}\right\}
$$

このよらに, $\phi_{x^{\circ} y}(\tau), \phi_{x^{\circ} \bar{y}}$ から $g(\tau, \bar{x}, u)$ を近似的に 得ることができる. しかし実際には出力 $y$ から $\bar{y}$ 分離することはむずかしく, $\phi_{x^{\circ} y}(\tau)$ が直接に求めら れる相関関数である. Fig. 4 は $\phi_{x^{\circ} y}(\tau)$ および $\phi_{x^{\circ} y}$ の一例であるが，この図からわかるようにてがじゅう ぶんに $N \Delta$ に近い值 $\tau^{\prime}\left(\tau^{\prime}<N \Delta\right)$ では (17) 式が成 立するように $N \Delta$ を選べば $\phi_{x^{\circ} y}\left(\tau^{\prime}\right)$ により $\phi_{x^{\circ} \bar{y}}$ 求めることができる.

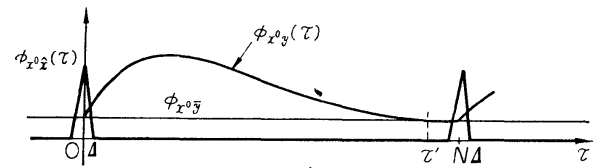

Fig. 4 Correlation functions $\phi_{x^{\circ} \hat{x}}(\tau), \phi_{x^{\circ} y}(\tau)$ and $\phi_{x^{\circ} \bar{y}}$

$$
\phi_{x^{\circ} y}\left(\tau^{\prime}\right) \doteqdot \phi_{x^{\circ} \bar{y}}
$$

また， $\phi_{x^{\circ} y}(\tau)$ の計算は普通は $\tau=p_{i} \Delta\left(p_{2}=1,2, \cdots\right.$ $N_{-1}$ ）の時点においてはきわめて容易である。したが って, $\tau, \tau^{\prime}$ を

$$
\tau=p_{i} \Delta, \quad \tau^{\prime}=q_{i} \Delta \quad\left(p_{i}<q_{i}\right)
$$

とおくと，(16) 式は（17）式を用いてつぎのように 表わすことができる。

$$
g(\tau, \bar{x}, u) \doteqdot \frac{2 N}{(N+1) a \Delta}\left\{\phi_{x^{\circ} y}\left(p_{i} \Delta\right)-\phi_{x^{\circ} y}\left(q_{i} \Delta\right)\right\}
$$

ただし $, p_{i}: 0,1,2, \cdots<q_{i}$

$$
q_{i}: N \text { に近くかつ } N \text { よ小さい自然数 }
$$

さて, プロセスの定常ゲイン $G(0, \bar{x}, u)$ と $g(\tau, \bar{x}, \cdot$ u）の間にはつぎの関係がある.

$$
G(0, \bar{x}, u)=\int_{0}^{\infty} g(\tau, \bar{x}, u) d \tau
$$

したがって（1）式から目的関数の傾きはつぎのよ らに表わされる。

$$
\left.\frac{\partial f(x, u)}{\partial x}\right|_{x=\bar{x}}=\int_{0}^{\infty} g(\tau, \bar{x}, u) d \tau
$$

すなわち, 目的関数の傾きは重み関数の面積で表わさ れる。(21) 式を $g\left(p_{i} \Delta, \bar{x}, u\right)$ で表わすと，

$$
\left.\frac{\partial f(x, u)}{\partial x}\right|_{x=\bar{x}}=\sum_{\imath=1}^{n} c_{i} g\left(p_{\imath} \Delta, \bar{x}, u\right)
$$

ここで， $c_{i}$ は面積補正係数である. $n$ の值を大きく， $N$ に近くとれば $c_{i} \doteqdot$ const. $(i=1,2, \cdots, n)$ となる.

(19）式および (22) 式から，目的関数の傾きに比 例するつぎのような值 $v$ を得ることができる。

$$
\begin{aligned}
v & =\sum_{i=1}^{n} c_{i}\left\{\phi_{x^{\circ} y}\left(p_{i} \Delta\right)-\phi_{x^{\circ} y}\left(q_{i} \Delta\right)\right\} \\
& \div\left.\frac{(N+1) a \Delta}{2 N} \cdot \frac{\partial f(x, u)}{\partial x}\right|_{x=\bar{x}}
\end{aligned}
$$

この $v$ を積分器を通して入力へフィードバックすれば 最適化制御系が構成される（Fig．5)，

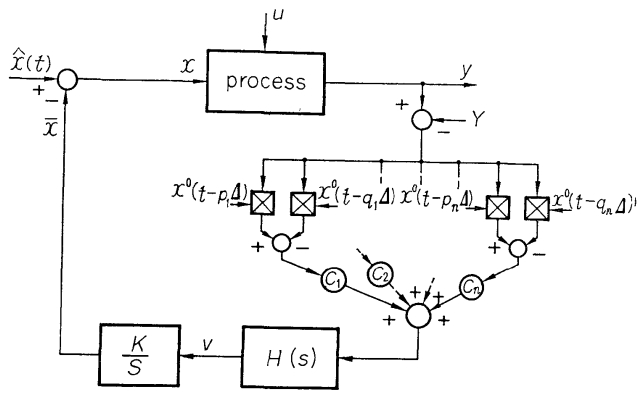

Fig. 5 Block diagram of optimizing control system. using $\mathrm{M}$-sequence signal

$$
\frac{d \bar{x}}{d t}=K v
$$

ここで,

$$
K \beta_{2}(\bar{x}, u)>0
$$

ただし，

$$
\beta_{2}(\bar{x}, u)=\left.\frac{\partial^{2} f(x, u)}{\partial x^{2}}\right|_{x=\bar{x}}
$$

相関関数 $\phi_{x^{\circ} y}\left(p_{i} \Delta\right), \phi_{x \circ y}\left(q_{i} \Delta\right)$ は (11) 式のように， $\mathrm{M}$-系列信号の周期 $N \Delta$ 間の平均值として定義される が，ここでは平均をと る操作を低域フィル タ ${ }^{11)} よ り$ 行なった。

Fig. 5 は M-系列信号 を用いた最適化制御系 のブロック線図であ る.ここで, $Y$ は目的 関数の最大值または最 小值であり, 掛算器の 手前で $y$ より引くこと

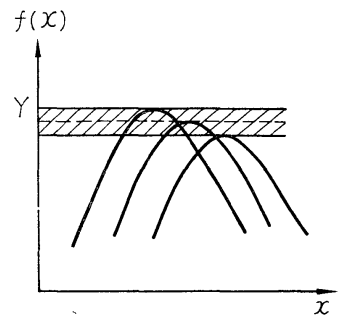

Fig. 6 An example of determing $\mathrm{Y}$ により低域フィルタの効果を大きくしている. Fig. 6 のように極値の大ささも変動する場合には，その平均 的な值でじゅうぶんであろう。

以上の解析は（3）式の $x$ について（4）式が成立 するという仮定に基づいてい。 しかし，プロセスが 


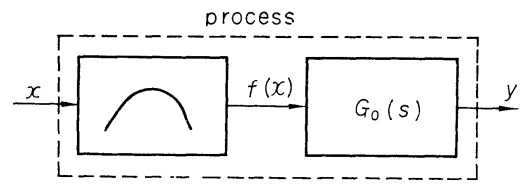

Fig. 7 A process

目的関数である非線形特性 $f(x, u)$ と線形特性 $G_{0}(s)$ とに分離でき，から Fig.7 のように $f(x, u)$ が $G_{0}(s)$ の前にあると考えることができる場合は（4）式の仮 定は次式におきか方られる。

$$
\begin{aligned}
f(x, u) & =f(\bar{x}, u)+\beta_{1}(\bar{x}, u)(x-\bar{x}) \\
& +\frac{1}{2} \beta_{2}(\bar{x}, u)(x-\bar{x})^{2}
\end{aligned}
$$

摂動損失 (perturbation loss) $L$ を一般的に求める のは困難であるが，プロセスが Fig. 7 のよらに分離 できる場合には $L$ は最大となり, 次式で求められる.

$$
L=\frac{a^{2}}{2}\left|\beta_{2}\left(\bar{x}_{0}, u\right) \cdot G_{0}(0)\right|
$$

ここで,

$$
\begin{aligned}
& \beta_{2}\left(\bar{x}_{0}, u\right)=\left.\frac{\partial^{2} f(x, u)}{\partial x^{2}}\right|_{x=\bar{x}_{0}} \\
& \left.\frac{\partial f(x, u)}{\partial x}\right|_{x=\bar{x}_{0}}=0
\end{aligned}
$$

\section{3. 動特性の変動の影響}

M-系列信号を用いるこの最適化制御系では運転中 のプロセスの動特性の変動は基本的には問題にならな い. 動特性の変動は Fig. 8 のように重及関数の変化 となって現われるが，その面積は変化しないからであ る.しかし, (22) 式の $n$ を小さくし, 一点か二点に 拈ける $g\left(p_{i} \Delta, \bar{x}, u\right)$ の值により全体の面積を近似する 場合はループゲインの変動となって動特性の変動の影 響が現わ机る。この場合必ずしも正確な面積を求め, ループゲインを一定に保つ必要はなく, むしろプロセ スの動特性の変動に応じてループゲインも変化するよ らな面積の測定をしたほうがよいと考えられる。たと えば，プロセスの定常ゲインは変化せず動特性だけが

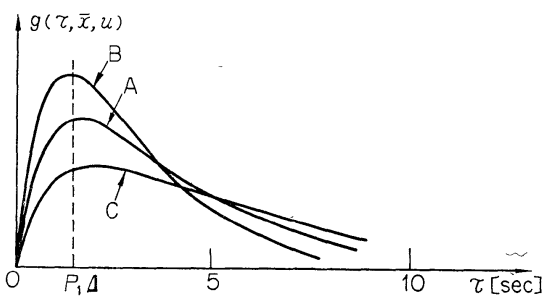

$$
\begin{aligned}
& \mathrm{A}: \mathcal{L}^{-1}\{1 /(s+1)(3 s+1)\} \\
& \mathrm{B}: \mathcal{L}^{-1}\{1 /(s+1)(2 s+1)\} \\
& \mathrm{C}: \mathcal{L}^{-1}\{1 /(s+1)(5 s+1)\}
\end{aligned}
$$

Fig. 8 An example of variable weghting function
Fig. 8 のからBに変化したとすると，この最適化制 御系の安定限界はAの場合より大きくなり,ループゲ インもそれに応じて大きくして差しつかえない。また， AからCに変わったならば安定限界はAの場合に比べ て小さくなり，ループゲインも小さくした核らがよい. $n=1$ とし， $p_{1}$ を Fig. 8 に示すような点にとれば， 面積の計算值は動特性の変動により誤差を生じるが, この場合の䛊差は上に述べたようにむしろ好ましい傾 向をもつものである. 実際にループゲインがその安定 限界值 ${ }^{811)}$ に比例するように $p_{i} \Delta$ を選ぶことは不可 能であるので, 最も安定性が悪くなる場合 (Fig.8で はC）にも系が安定となるよらにフィードバックルー プの積分器のゲインを設定することが必要である.

\section{4. 多変数同時最適化制御}

M-系列信号はその擬似ランダムといら性質から多 入力ー単出力プロセス, すなわち多変数プロセスの動 特性の同時測定に用いることがでさる12). したがって $\mathrm{M}$ 一系列信号による多変数同時最適化制御が可能であ ある・

$r$ 個の入力 $x_{1}, x_{2}, \cdots, x_{r}$ 之 1 個の出力 $y$ をもつ Fig. 9 のよらなプロセスを考光る. 操業入力を $\bar{x}_{\hat{j}}$,

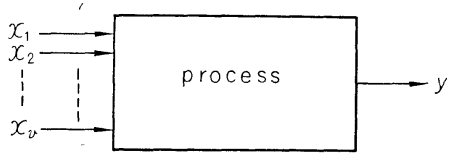

Fig. 9 A multi-variable process

$(j=1,2, \cdots r)$ とし， $\bar{x}_{j}$ から $y$ までの伝達関数を $G_{\bar{J}}$ $(s, \overline{\boldsymbol{X}}, \boldsymbol{u}),\left(\overline{\boldsymbol{X}}=\left(\bar{x}_{1}, \bar{x}_{2}, \cdots, \bar{x}_{r}\right)\right)$ とすれば，各変数 $x_{j}$ に関する目的関数の傾きはつぎのように表わされる.

$$
\left.f_{x_{j}}(\boldsymbol{X}, \boldsymbol{u})\right|_{x=\bar{\Delta}}=G_{j}(0, \boldsymbol{X}, \boldsymbol{u})
$$

ここで,

$$
\begin{array}{ll} 
& f_{x_{j}}(\boldsymbol{X}, \boldsymbol{u}) \\
\text { ただし }, & \boldsymbol{X}_{\boldsymbol{X}=\overline{\boldsymbol{X}}}=\left.\frac{\partial f(\boldsymbol{X}, \boldsymbol{u})}{\partial x_{j}}\right|_{\boldsymbol{x}=\overline{\boldsymbol{X}}}
\end{array}
$$

着目する $\bar{x}_{j}$ の範囲を

$$
\begin{gathered}
\bar{x}_{j * \leq} \leq \bar{x}_{j} \leq \bar{x}_{j}{ }^{*} . \\
(j=1,2, \cdots, r)
\end{gathered}
$$

とし，この $\bar{x}_{j}$ に関して $r$ 個の方程式

$$
\begin{aligned}
& f_{x_{\jmath}}(\boldsymbol{X}, \boldsymbol{u})=0 \\
& (j=1,2, \cdots, r)
\end{aligned}
$$

はそれぞれ根を 1 個ずつもち，このプロセスの最適点 は (34) 式を $r$ 元の連立方程式とした場合の根

$$
\overline{\boldsymbol{X}}_{0}{ }^{\prime}=\left(\bar{x}_{10}, \bar{x}_{20}, \cdots, \bar{x}_{r 0}\right)
$$

であるとする.すなおち，

$$
\left.f_{x_{3}}(\boldsymbol{X}, \boldsymbol{u})\right|_{\boldsymbol{x}=-0}=0
$$




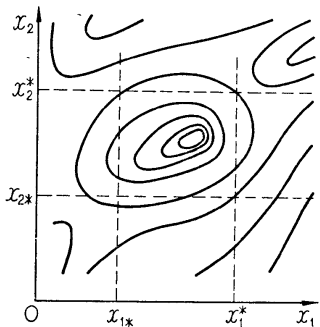

Fig. 10 An example of objective function of two-variable process

Fig. 10 は $r=2$ の場合の目的関数の例である.ま た微小区間

$$
\bar{x}_{j}-a_{j} \leq x_{j} \leq \bar{x}_{j}+a_{j}
$$

においては $f_{x_{j}}(\boldsymbol{X}, \boldsymbol{u})$ はつぎのように近似できるとす る.

$$
\begin{aligned}
f(\boldsymbol{X}, \boldsymbol{u}) & =f(\overline{\boldsymbol{X}}, \boldsymbol{u})+\beta_{11}(\overline{\boldsymbol{X}}, \boldsymbol{u})\left(x_{1}-\bar{x}_{1}\right)+\cdots \\
& +\beta_{1 j}(\boldsymbol{X}, \boldsymbol{u})\left(x_{j}-\bar{x}_{j}\right)+\cdots+\beta_{1 r}(\overline{\boldsymbol{X}}, \boldsymbol{u})\left(x_{r}-\bar{x}_{r}\right)
\end{aligned}
$$

ただし

$$
\beta_{1 j}(\overline{\boldsymbol{X}}, \boldsymbol{u})=\left.\frac{\partial f(\boldsymbol{X}, \boldsymbol{u})}{\partial x_{j}}\right|_{X=\bar{X}}
$$

（38）式は一変数系の場合の式（4）飞対応するもの である。

各入力 $\bar{x}_{j}$ に加える $\mathrm{M}$-系列信号の振幅を $a_{j}$ とし, 一変数系の場合と同様に $\left.f_{x_{j}}(\boldsymbol{X}, \boldsymbol{u})\right|_{x=\bar{x}}$ を測定する ことができるが，この場合は $\left.f_{x_{j}}(\boldsymbol{X}, \boldsymbol{u})\right|_{x=\bar{x}}$ が独立 に求まるように探索信号を決める必要がある，考光ら れる方法としては, Fig. 11 のようにすべての $g_{j}(\tau$, $\overline{\boldsymbol{X}}, \boldsymbol{u})$ が重ならないように探索信号

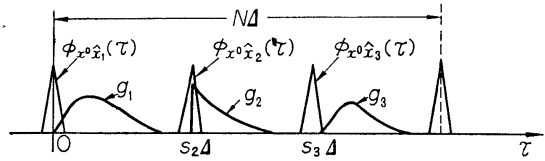

Fig. 11 Correlation functions and weighting functions of simultaneous optimizing control system of multi-variable process

$$
\hat{x}_{j}(t)=\hat{x}\left(t-S_{j} \Delta\right)
$$

の $S_{j} \Delta$ を選ぶ方法がある. $g_{j}(\tau, \overline{\boldsymbol{X}}, \boldsymbol{u})$ は $G_{j}(s, \overline{\boldsymbol{X}}$, u）を逆ラプラス変換したものである.この $S_{j} \Delta$ は次 式を満足するように決定される。

$$
\begin{gathered}
g_{j}\left(S_{j+1} \Delta-S_{j} \Delta, \quad \overline{\boldsymbol{X}}, \boldsymbol{u}\right) \div 0 \\
(j=1,2, \cdots, r) \\
S_{1}=0, \quad S_{r+1}=N
\end{gathered}
$$

$g_{j}\left(p_{j i} \Delta-S_{j-1} \overline{\Delta,} \boldsymbol{X}, \boldsymbol{u}\right)$ と $\phi_{x^{\circ} y_{y}}\left(p_{j i} \Delta\right), \phi_{x \circ_{y}}\left(q_{j i} \Delta\right)$ の関
係は一変数系の場合と同様に次式のようになる.

$g_{j}\left(p_{j \imath} \Delta-S_{j} \Delta, \overline{\boldsymbol{X}}, \boldsymbol{u}\right)$

$$
=\frac{2 N}{(N+1) a \Delta}\left[\phi_{x^{\circ} y}\left(p_{j i} \Delta\right)-\phi_{x^{\circ} y}\left(q_{j i} \Delta\right)\right]
$$

ただし，

$$
p_{j i}=S_{j}, S_{j}+1, \cdots, S_{j+1}-1
$$

また， $q_{j i} \Delta$ は次式を満足するように選ばれる.

$$
\phi_{x^{\circ} y}\left(q_{j i} \Delta\right) \doteqdot \phi_{x^{\circ} \bar{y}}
$$

さらに，(22) 式に対応して次式が得られる。

$$
\left.\frac{\partial f(\boldsymbol{X}, \boldsymbol{u})}{\partial x_{j}}\right|_{\boldsymbol{X}=\overline{\boldsymbol{4}}} \div \sum_{i=1}^{n_{j}} C_{j i} g_{j}\left(p_{j i} \Delta-S_{j} \Delta, \overline{\boldsymbol{X}}, \boldsymbol{u}\right)
$$

したがって，(42) 式，(45) 式からつぎの関係が得ら れる。

$$
\begin{aligned}
v_{j} & =\sum_{i=1}^{n_{j}} C_{j i}\left\{\phi_{x^{\circ} y}\left(p_{j i} \Delta\right)-\phi_{x^{\circ} y}\left(q_{j i} \Delta\right)\right\} \\
& \left.\doteqdot \frac{(N+1) a \Delta}{2 N} \cdot \frac{\partial f(\boldsymbol{X}, \boldsymbol{u})}{\partial x_{j}}\right|_{x=\bar{X}}
\end{aligned}
$$

$v_{j}$ は積分器を通して各入力ヘフィードバックされる.

$$
\frac{d \bar{x}_{j}}{d t}=K_{j} v_{j}
$$

ただし，

$$
K_{j} \cdot \beta_{2 j}(\overline{\boldsymbol{X}}, \boldsymbol{u})>0
$$

ここで

$$
\beta_{2 j}(\overline{\boldsymbol{X}}, \boldsymbol{u})=\left.\frac{\partial^{2} f(\boldsymbol{X}, \boldsymbol{u})}{\partial x_{j}{ }^{2}}\right|_{x=-}
$$

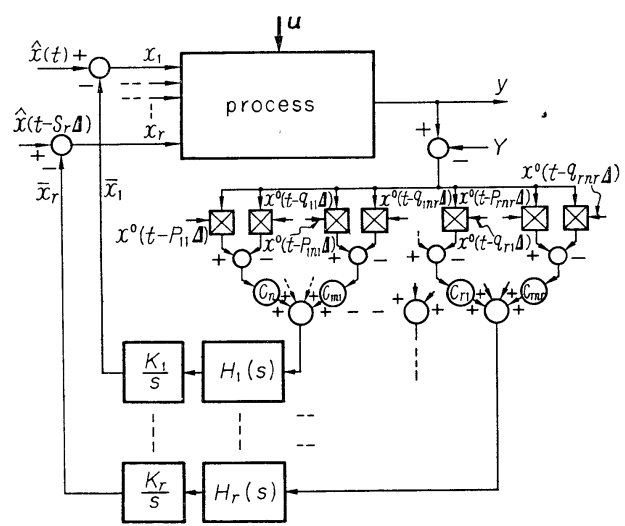

Fig. 12 Block diagram of simultaneous optimizing control system using $\mathrm{M}$-sequences

吾Fig. 12 は M-系列信号を用いた多変数同時最適化 制御系のブロック線図である。

な拉，プロセスが Fig. 13 のように考兄られる場 合は (38) 式の仮定は (50) 式に扣きかえられる. $f_{x_{j}}(\boldsymbol{X}, \boldsymbol{u})=\beta_{1 j}(\overline{\boldsymbol{X}}, \boldsymbol{u})+\beta_{2 j}(\overline{\boldsymbol{X}}, \boldsymbol{u})\left(x_{j}-\bar{x}_{j}\right)$ ただし， 


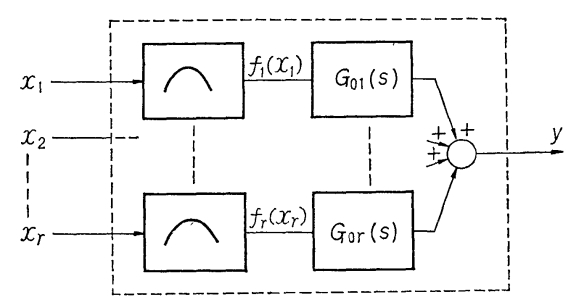

Fig.13 A multi-variable process

$$
\beta_{2 j}(\overline{\boldsymbol{X}}, \boldsymbol{u})=\left.\frac{\partial f(\boldsymbol{X}, \boldsymbol{u})}{\partial x_{j} \partial x_{j}}\right|_{.=\bar{x}}
$$

\section{5. アナログ電子計算機による検討}

プロセスが Fig. 7 のように非線形特性 $f(x)$ と線 形特性 $G_{0}(s)$ に分離できる場合について,アナログ電 子計算機を用いて行なった実験の結果を以下に示す.

\section{$5 \cdot 1$ 一変数最適化制御}

\section{[実験 1]}

プロセス

$f(x)=-0.5 x^{2}, \quad G_{0}(s)=\frac{1}{(s+1)(3 s+1)}$

M-系列信号

$$
N=31, \quad \Delta=0.5 \mathrm{sec}, \quad a=3
$$

掛 算 器

$n=1, \quad p_{1}=3, \quad q_{1}=30, \quad c_{1}=5.25, \quad Y=0$

フィルタ

$$
H(s)=\frac{1}{(6.7 s+1)^{2}}
$$

積分器ゲイン

$$
K=0.08
$$

摂動損失

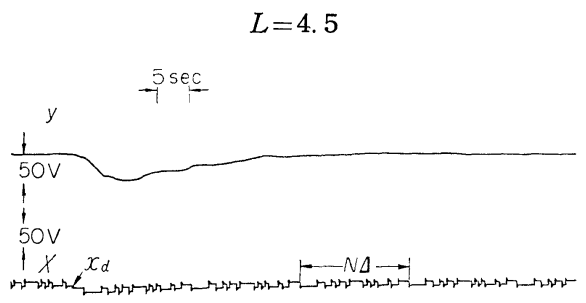

Fig. 14 Optimizing process when a stepwise input disturbance $X_{d}$ is inserted (experiment 1)

Fig. 14 は入力にステップ状外乱 $x_{d}$ がはいった場 合の最適点追従の過程を示す.

\section{$5 \cdot 2$ 動特性の変動の影響}

実験 1 の最適化制御系についてプロセスの動特性を 変動させ, その場合の最適点追従の実験を行なった。

[実験 2]

実験 1 の系においてほかのものはそのままにし，時 定数のみを変えた。

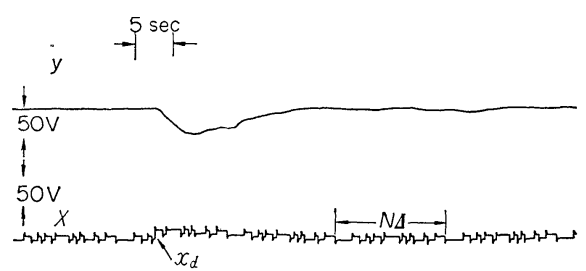

Fig. 15 Optimizing process with $T=2 \mathrm{sec}$ (experiment 2)

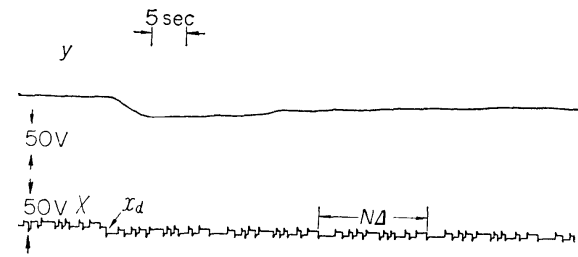

Fig. 16 Optimizing process with $T=5 \mathrm{sec}$ (experiment 2)

プロセス

$$
G_{0}(s)=\frac{1}{(s+1)(T s+1)}
$$

Fig. 15 および Fig. 16 はそれぞれ $T=2 \mathrm{sec} ， T$ $=5 \mathrm{sec}$ に変え, 入力にステップ状外乱 $x_{d}$ を加えた 場合の最適点追従の過程を示す. Fig. 8 はそれらに対 するプロセスの重久関数を示す．また，Tの変化に対 するループゲインの変化，およびループゲインの安定 限界值の変化は Table 1 に示すと括りである.

\begin{tabular}{c|c|c|c|c|c}
\hline$T$ & $g_{0}\left(p_{1} \Delta\right)$ & $c_{1} g_{0}\left(p_{1} \Delta\right)$ & $K_{l}$ & $K_{l c}$ & $K_{l} / K_{l c}$ \\
\hline 2 & 0.25 & 1.3 & 0.08 & 0.17 & 0.47 \\
3 & 0.19 & 1.0 & 0.06 & 0.16 & 0.38 \\
5 & 0.13 & 0.7 & 0.04 & 0.13 & 0.32 \\
\hline
\end{tabular}

\section{Table 1}

\section{$5 \cdot 3$ 二変数同時最適化制御}

\section{[実験 3]}

$$
\begin{aligned}
& \text { プロセス (Fig. 13) } \\
& f_{1}\left(x_{1}\right)=-0.24 x_{1}{ }^{2}, \quad f_{2}\left(x_{2}\right)=-0.32 x_{2}{ }^{2} \\
& G_{01}(s)=\frac{1}{(s+1)(3 s+1)}, \quad G_{02}(s)=\frac{1}{s+1}
\end{aligned}
$$

M-系列信号

$$
\begin{array}{ll}
N=31, & \Delta=1 \mathrm{sec}, \quad a_{1}=3, \quad a_{2}=3 \\
s_{1}=0 & s_{2}=17
\end{array}
$$

掛算器

$$
\begin{aligned}
& n_{1}=1, \quad p_{11}=3, \quad q_{11}=30, \quad c_{11}=5, \quad n_{2}=1, \\
& \quad p_{21}=18, \quad q_{21}=16, \quad c_{21}=1.7, \quad Y=0 \\
& \text { フィルタ } \\
& \quad H_{1}(s)=\frac{1}{(14.3 s+1)^{2}}, \quad H_{2}(s)=\frac{1}{(12.5 s+1)^{2}}
\end{aligned}
$$

積分器ゲイン 


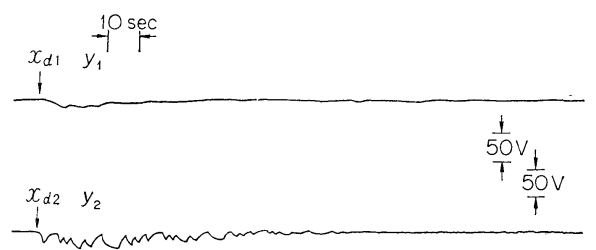

Fig. 17 Optimizing process of two variable system when stepwise input disturbance $X_{d_{1}}$ and $X_{d_{2}}$ are inserted (experiment 3 )

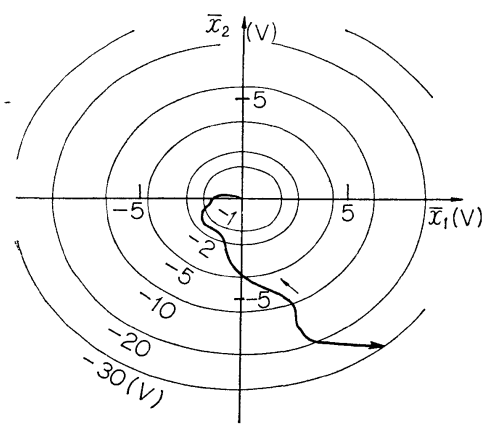

Fig 18 Hill climbing trajectory (experiment 3 )

$$
K_{1}=0.007 \quad K_{2}=0.03
$$

摂動損失

$$
L=5
$$

Fig. 17 は入力 $x_{1}, x_{2}$ にそれぞれステップ状外乱 $x_{d_{1}}, x_{d_{2}}$ を加光た場合で, Fig. 18 はそのときの山登 りの過程を示したものである。

\section{6. 結 言}

ここでは M-系列信号を探索信号として用いた最適 化制御系の検討を行なったが，この方法は従来相関形 正弦波摂動法のもつ欠点とされていた点をかなり補ら
ことができ，実際に有力な手法であると思われる，相 関器に用いる掛算器として，リレーが使用できるとい ら点もこの方法が実際面で持つ利点であろら.

おおりに，本研究にあたり助言をいただいた東京工 業大学・森永智昭助教授, 市川惊信助教授に, また実 験その他に協力いただいた岩佐公一氏に心から感謝の 意を表する。

$$
\text { 文献 }
$$

1) 藤井, 古賀 : “相関形最適化制御系の解析“ 日本機械 学会論文集, 26-161，pp. 129-138 (1960)

2）福永，井上：“探索信号を用いた最適化制御” 制御工 学, 6-4, pp. 207-213 (1962)

3）市川：“化学工業に和汀る最適化”ケミカルエンジニ アリング，9-4，5，6 (1963)

4) C. S. Draper \& Y. T. Li : "Principle of Optimalizing Control Systems andan Application to the Internal Combustion Engine" ASME Publication (1951)

5) P.Eykhoff \& O. J.M.Smith : "Optimizing Cotrol with Process Dynamics Identification” IRE Trans. on A.C., 7, pp. 140-155 (1962)

6) P.M.E.M.van der Grinten : "The application of random test signals in process optimization" Proceedings of the 2 nd congress IFAC Basle 1963 Theory, 551-555

7）磯 部, 間野: “探索信号法による多变数系の最適化制 御の一方法” 計測自動制御学会第 4 回学術講演会予稿 集, pp. 273-274 (1965)

8）伊沢，古田，大地：“最適化制御系の安定性に関する 研究” 第 8 回自動制御連合会講演会前刷, pp. 123-124 (1965)

9) D. A. Huffman: "The Synthesis of Linear Sequential Coding Networks" Information theory, pp. 77-95 (Academic Press-1956)

10）伊沢，古田：“プロセス動特性の一測定法”計測と制 御, 3-9, pp. 21-29 (1964)

11）大地：“最適化制御に関する研究” 東京工業大学修士 論文 (1965)

12) K. Izawa and K. Furuta : "Simultaneous identification of multi-input and -output systems" Preprint IFAC Tokyo symposium IV, 1-11 (1965) 